\title{
Evaluation of the Detection Efficiency of LYSO Scintillator in the Fiber-Optic Radiation Sensor
}

\author{
Chan Hee Park, Arim Lee, Rinah Kim, and Joo Hyun Moon \\ Dongguk University, Gyeongju Campus, 123 Dongdae-ro, Gyeongju, Republic of Korea \\ Correspondence should be addressed to Joo Hyun Moon; jhmoon86@dongguk.ac.kr
}

Received 18 December 2013; Accepted 21 February 2014; Published 6 April 2014

Academic Editor: Jakrapong Kaewkhao

Copyright (c) 2014 Chan Hee Park et al. This is an open access article distributed under the Creative Commons Attribution License, which permits unrestricted use, distribution, and reproduction in any medium, provided the original work is properly cited.

\begin{abstract}
The aim of this study was to develop and evaluate fiber-optic sensors for the remote detection of gamma rays in areas that are difficult to access, such as a spent fuel pool. The fiber-optic sensor consists of a light-generating probe, such as scintillators for radiation detection, plastic optical fibers, and light-measuring devices, such as $\mathrm{PMT}$. The $(\mathrm{Lu}, \mathrm{Y})_{2} \mathrm{SiO}_{5}: \mathrm{Ce}(\mathrm{LYSO}$ :Ce) scintillator was chosen as the light-generating probe. The $(\mathrm{Lu}, \mathrm{Y})_{2} \mathrm{SiO}_{5}: \mathrm{Ce}(\mathrm{LYSO}: \mathrm{Ce})$ scintillator has higher scintillation efficiency than the others and transmits light well through an optical fiber because its refraction index is similar to the refractive index of the optical fiber. The fiber-optic radiation sensor using the $(\mathrm{Lu}, \mathrm{Y})_{2} \mathrm{SiO}_{5}: \mathrm{Ce}(\mathrm{LYSO}: \mathrm{Ce})$ scintillator was evaluated in terms of the detection efficiency and reproducibility for examining its applicability as a radiation sensor.
\end{abstract}

\section{Introduction}

Workers should take extreme care when approaching high radiation areas, such as areas neighboring highly radioactive equipment or spent fuel pool, due to the risks of radiation exposure. To detect the radiation levels in those areas, it is necessary to develop a remote radiation detection system. The radiation levels surrounding the spent fuel pool are generally measured using the fixed type radiation detector system. Sometimes, the radiation levels on the water surface of the pool need to be measured using a portable radiation detector that a worker brings to the measurement point.

Optical fibers have been applied for remote radiation detection. Optical fibers have several advantages: intrinsic insensitivity to magnetic fields and electromagnetic interference, small size, and ability to perform distributed radiation measurements along a single fiber using optical time domain reflectometry techniques [1]. The applications of optical fiber technology include local dose deposition measurements and distributed hot-spots dose monitoring in nuclear waste storage facilities $[2,3]$. The development of optical fiber radiation sensors has been driven mostly by medical applications such as in vivo real-time dosimetry [4]. The possibility of distributed optical fiber sensing technology was proven by monitoring the large nuclear infrastructures, such as reactor containment buildings and radioactive waste repositories [5].

Optical fiber can be used not only as a radiation sensor but also as a medium for transmitting the light generated by a scintillator. In the field of X-ray and gamma ray medical imaging modalities, inorganic scintillators were selected as radiation in light converters [6-8]. The $(\mathrm{Lu}, \mathrm{Y})_{2} \mathrm{SiO}_{5}$ :Ce(LYSO:Ce) scintillator was used for medical imaging [9]. This study adopted a $(\mathrm{Lu}, \mathrm{Y})_{2} \mathrm{SiO}_{5}$ :Ce(LYSO:Ce) scintillator as the scintillator, which was connected to the optical fiber.

This paper developed and evaluated a radiation sensor using an optical fiber for the remote detection of gamma rays in real time in areas that are difficult to access, such as the spent fuel pool.

\section{Method}

2.1. Material Selection and Characteristic Study of Optic Fibers and Scintillators. The fiber-optic radiation sensor consisted of a radiation sensing probe, transmitting optical fiber, and data acquisition instruments. The fiber-optic radiation sensor should have a long transmitting optical fiber because it needs 
TABLE 1: Main characteristics of inorganic scintillators [11].

\begin{tabular}{|c|c|c|c|c|c|}
\hline Scintillator & BGO & YSO:Ce & LYSO:Ce & CsI:Tl & LSO:Ce \\
\hline Effective $Z$ number & 83 & 35 & 65 & 51 & 66 \\
\hline Density $\left(\mathrm{g} / \mathrm{cm}^{3}\right)$ & 7.13 & 4.45 & 7.20 & 4.51 & 7.40 \\
\hline Melting point $\left({ }^{\circ} \mathrm{C}\right)$ & 1,050 & 2,470 & 2,100 & 621 & 2,050 \\
\hline Refractive index & 2.15 & 1.80 & 1.82 & 1.79 & 1.82 \\
\hline $\begin{array}{l}\text { Light yield (\%) } \\
{ }^{*} \text { relative to } \mathrm{NaI}: \mathrm{Tl}\end{array}$ & $15 \sim 20$ & 80 & $73 \sim 75$ & $50 \sim 100$ & $\sim 75$ \\
\hline Peak wavelength (nm) & 480 & 420 & 420 & 540 & 420 \\
\hline Decay time (ns) & 300 & 70 & 42 & 1100 & 40 \\
\hline
\end{tabular}

to detect the radiation level at a point far away from the radiation source.

This study chose a scintillator suitable for measuring gamma rays and evaluated its performance according to the optical fiber length. In general, the scintillator for gamma spectroscopy is the inorganic scintillator with a high atomic number. Table 1 shows that the light yield of the LYSO was approximately 4 times higher than the BGO. The scintillating materials with Ce-doped oxyorthosilicates are used in various fields. The $\mathrm{Lu}_{2} \mathrm{SiO}_{5}: \mathrm{Ce}$ (LSO:Ce) was widely known as very efficient, especially for medical imaging applications. It is due to high stopping power resulting from its high density, high light output, and fast response. The $(\mathrm{Lu}, \mathrm{Y})_{2} \mathrm{SiO}_{5}: \mathrm{Ce}(\mathrm{LYSO}: \mathrm{Ce})$ shows similar properties. But the $\mathrm{Lu}_{2} \mathrm{SiO}_{5}: \mathrm{Ce}(\mathrm{LSO}: \mathrm{Ce})$ is of high cost. $(\mathrm{Lu}, \mathrm{Y})_{2} \mathrm{SiO}_{5}: \mathrm{Ce}(\mathrm{LYSO}: \mathrm{Ce})$ is a promising next generation scintillation crystal that is cheaper to produce [10]. Finally, the $(\mathrm{Lu}, \mathrm{Y})_{2} \mathrm{SiO}_{5}: \mathrm{Ce}(\mathrm{LYSO}: \mathrm{Ce})$ was selected as the sensing probe of the fiber-optic sensor to detect gamma rays. This scintillator has an advantage for the remote detection of gamma rays because of its high density, high light output, fast decay time, good radiation hardness, high effective atomic numbers, nonhygroscopicity and stable physical and chemical properties, and ease of combining with the optical fiber. The $(\mathrm{Lu}, \mathrm{Y})_{2} \mathrm{SiO}_{5}: \mathrm{Ce}(\mathrm{LYSO}: \mathrm{Ce})$ scintillator has a higher scintillation efficiency than the others and transmits light well through optical fibers because its refraction index is almost equal to the refractive index of the optical fiber. The $(\mathrm{Lu}, \mathrm{Y})_{2} \mathrm{SiO}_{5}: \mathrm{Ce}(\mathrm{LYSO}: \mathrm{Ce}$ ) scintillator (Advanced Microwave Technologies Solution Co., Ltd) was $3 \mathrm{~mm}$ in diameter and $20 \mathrm{~mm}$ in length. The scintillator is cylinder type consistent with diameter of the optic fiber for easy to combine scintillator with optic fiber. To improve efficiency of light receiving, the surface of the scintillator is wrapped by Teflon reflective tape, attaching the holder to minimize the interference from ambient light. Table 1 lists the characteristics of the inorganic scintillators, including the $(\mathrm{Lu}, \mathrm{Y})_{2} \mathrm{SiO}_{5}: \mathrm{Ce}(\mathrm{LYSO}: \mathrm{Ce})$.

The optical fiber normally used in the communication field is a glass optic fiber (GOF) made of quartz glass with high purity. The wide use of quartz glass optical fiber is due mainly to its outstanding optical properties, environmental safety, and thermal resistance. Although glass fibers have better thermal resistance than plastic fibers, glass fibers are fragile, difficult to be made into goods of any shape, and expensive. Therefore, the optic materials of high polymer
TABle 2: Properties of the plastic optic fiber.

\begin{tabular}{lc}
\hline \multicolumn{1}{c}{ Plastic optic fiber (NY02, Edmund optics) } \\
\hline Core & PMMA \\
Clad & Fluorine-PMMA \\
Numerical aperture & 0.50 \\
Operating temperature & $-55^{\circ} \mathrm{C} \sim+70^{\circ} \mathrm{C}$ \\
Minimum radius of band & $25 \times$ outer diameter \\
\hline
\end{tabular}

TABle 3: Properties of the photomultiplier.

\begin{tabular}{lc}
\hline Parameter & Description \\
\hline Wavelength, nm & $300-650$ \\
Peak wavelength, nm & 420 \\
Cathode & Bialkali \\
& 22 \\
Dynode & $\mathrm{L}$ \\
Rise time, ns & 10 \\
\hline
\end{tabular}

have rapidly replaced glass optical fibers. Among them, plastic optic fibers (POFs) are the most widely used.

This study selected a plastic optic fiber (NY02, Edmund optics) with a diameter of $3 \mathrm{~mm}$. NY02 consists of a core made of polymethylmethacrylate (PMMA) and a cladding made of fluorine polymethylmethacrylate (F-PMMA). Table 2 lists the properties of the plastic optic fibers chosen in this study.

2.2. Experimental Setup. The light-measuring device used in this study consisted of a radiation sensor probe, transmitting plastic optic fiber, photomultiplier tube (PMT), amplifier (AMP), and multichannel analyzer (MCA). The PMT used for the measurement was a H5211A (Hamamatsu), whose properties are summarized in Table 3. The PMT has response wavelengths of $300-650 \mathrm{~nm}$ as a head-on type. The main amplifier was the Canberra Amplifier model 2012. A power supply (C3830, Hamamatsu) was used to supply electric power to the PMT and preamplifier safely and simultaneously. The Ortec trump-8k-32+Maestro32 was used as the multichannel analyzer.

Figure 1 shows the experimental setup for a performance assessment of the remote fiber-optic radiation sensors. The fiber-optic radiation sensor was fabricated by attaching 


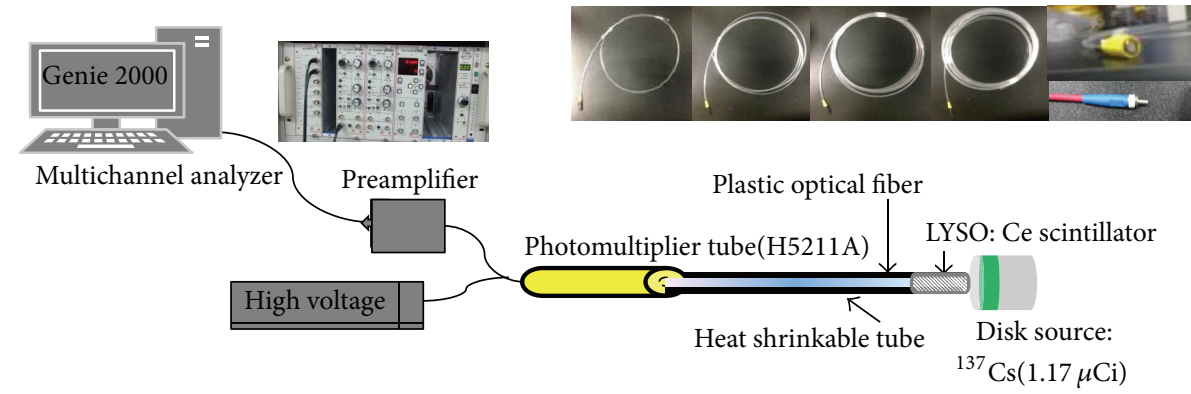

FIGURE 1: Experimental setup.

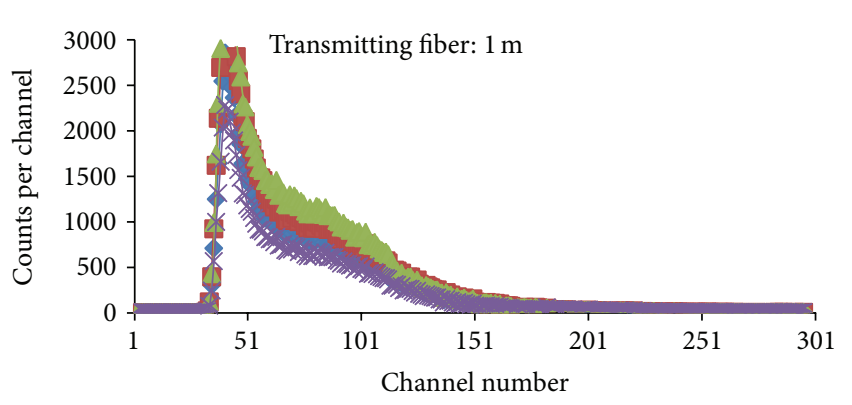

(a)

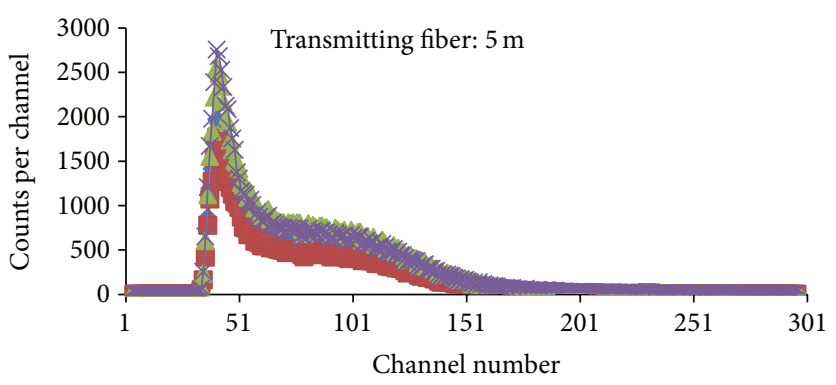

(c)

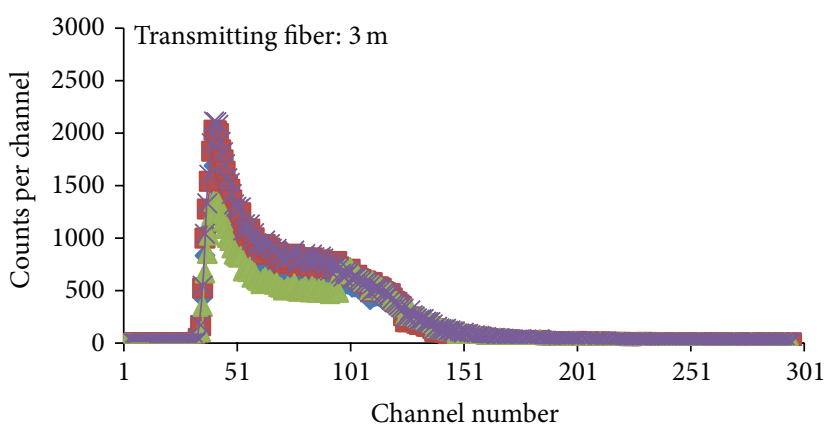

(b)

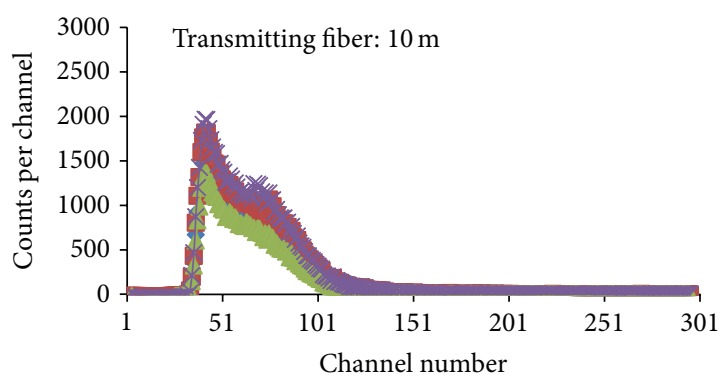

(d)

FIGURE 2: Reproducibility evaluation results of the fiber-optic radiation sensors according to the length of the transmitting optical fiber.

a scintillator to one-side end of the optical fiber using epoxy resin. To examine the effects of the length of the transmitting optical fiber, 4 types of the fiber-optic radiation sensors were fabricated: 1, 3, 5, and $10 \mathrm{~m}$ long. During the measurements, the bending angle of each fiber-optic radiation sensor was set to be the same so each optical fiber would have the same bending loss.

\section{Results}

Figure 2 shows the pulse height spectra of the fiber-optic radiation sensors against a Cs-137 source according to the length of the transmitting optical fiber. The reproducibility was evaluated 4 times according to the length of the optical fiber. Although the length changes, the overall shapes of the pulse height spectra were similar, except the case when the peak of the spectra when the length of the transmitting optical fiber was $1 \mathrm{~m}$ was much higher than the other cases. On the other hand, the fiber-optic radiation sensor, $10 \mathrm{~m}$ in length, had the smallest standard deviation. The measurements showed that the $10 \mathrm{~m}$ long fiber-optic sensor can be used as a remote radiation sensor.

Figure 3 shows the pulse height spectra and total counts on average according to the length of the transmitting optic fiber. Similar to the reproducibility evaluation results, the comparison between the $1 \mathrm{~m}$ long transmitting optic fiber and others showed that the total counts by the $1 \mathrm{~m}$ long transmitting optic fiber were approximately $25-40 \%$ higher than the others.

Figure 4 shows the pulse height spectra according to the distance between the radiation sensor and the source, 0,1 , and $5 \mathrm{~cm}$ using the $1 \mathrm{~m}$ long transmitting optical fiber. The reproducibility was measured 4 times with the same distance between the radiation sensor and source. The shapes of the spectra of the 4 sensors were similar, but Figure 4 shows 


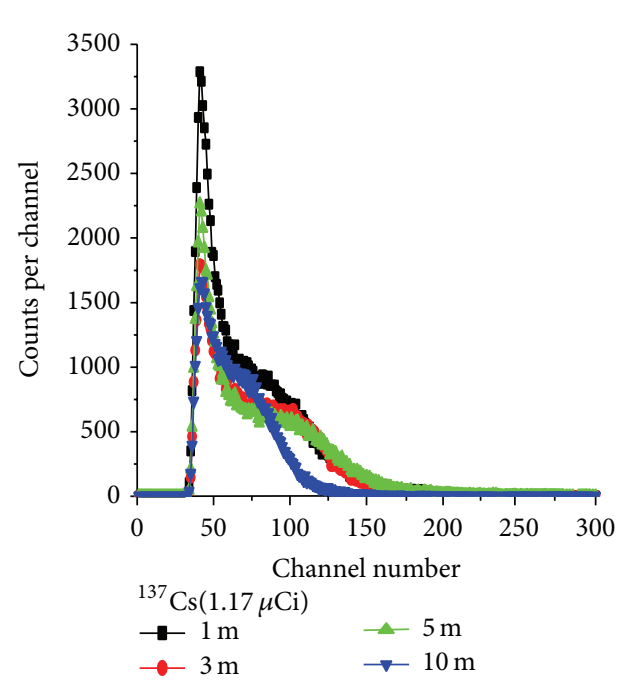

(a)

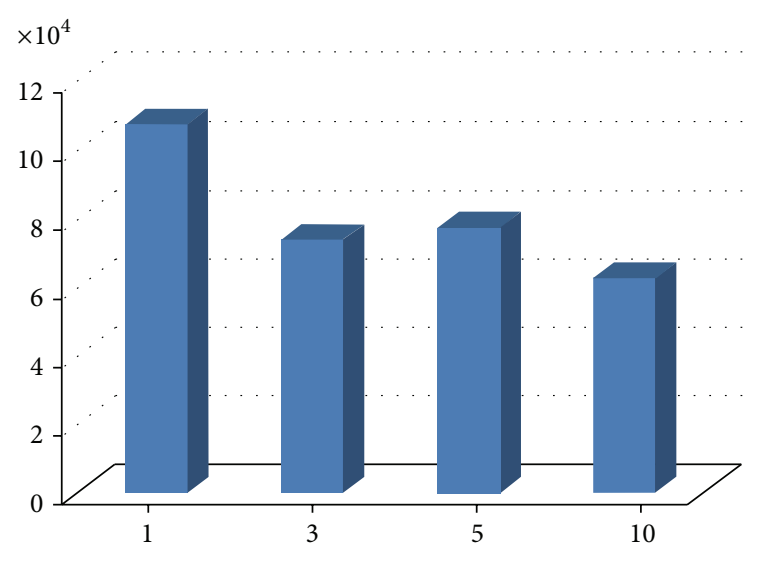

(m)

(b)

FIGURE 3: Pulse height spectra on the length of the transmitting optic fiber.

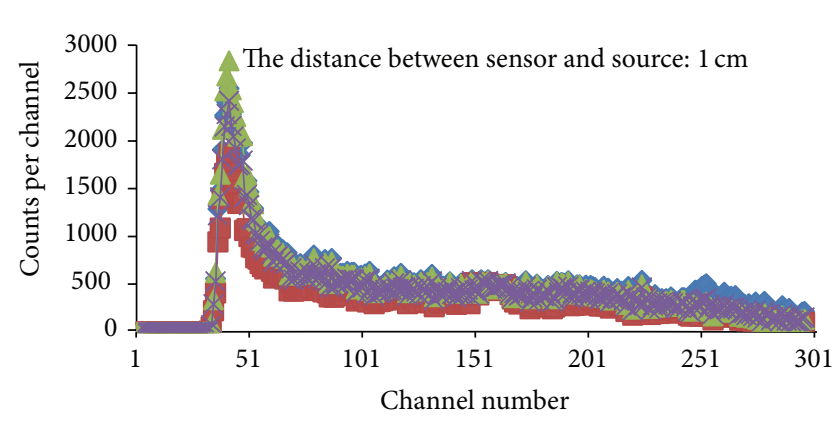

(a)

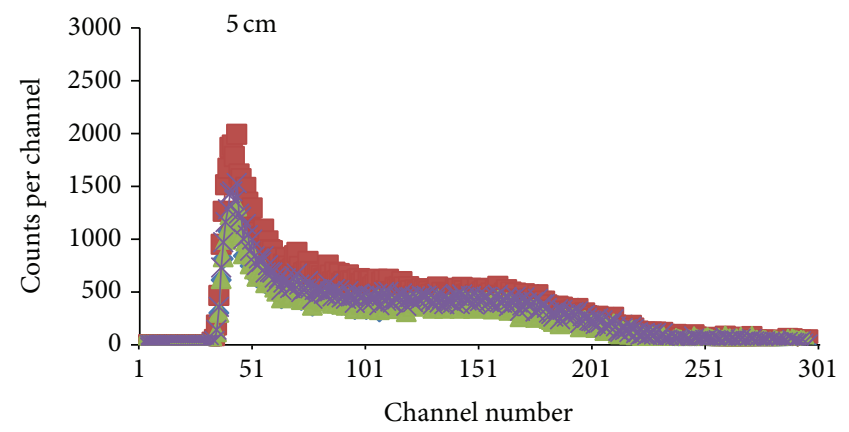

(b)

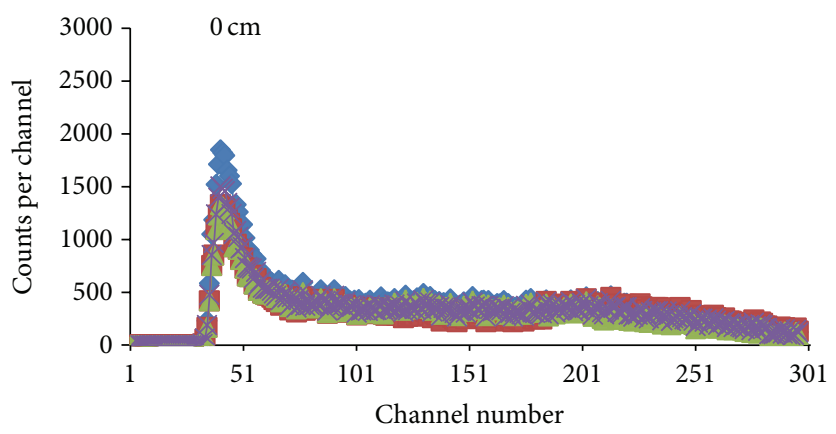

(c)

FIGURE 4: Reproducibility evaluation on the distance between the radiation sensor and the source.

that the efficiency of the case where the distance between the radiation sensor and source was $1 \mathrm{~cm}$ was higher than the other cases. On the other hand, the distance between the radiation and the source of $0 \mathrm{~cm}$ was found to have the smallest standard deviation.

Figure 5 shows the total counts according to (a) transmitting fiber length and (b) the distance between the fiber-optic sensor and source, respectively. As shown in Figure 5(a), the detection efficiency of the transmitting fiber length of $1 \mathrm{~m}$ was the best, but the deviation in the total counts for the transmitting fiber length of $10 \mathrm{~m}$ was the lowest. The standard deviations in the total counts for 4 cases of the transmitting fiber length were 12 to $20 \%$. In Figure 5(b), the detection efficiency for a distance of $1 \mathrm{~cm}$ between the fiber-optic sensor and radiation source was found to be the best. The standard deviations of the total counts for the 3 cases were less than $5 \%$. 


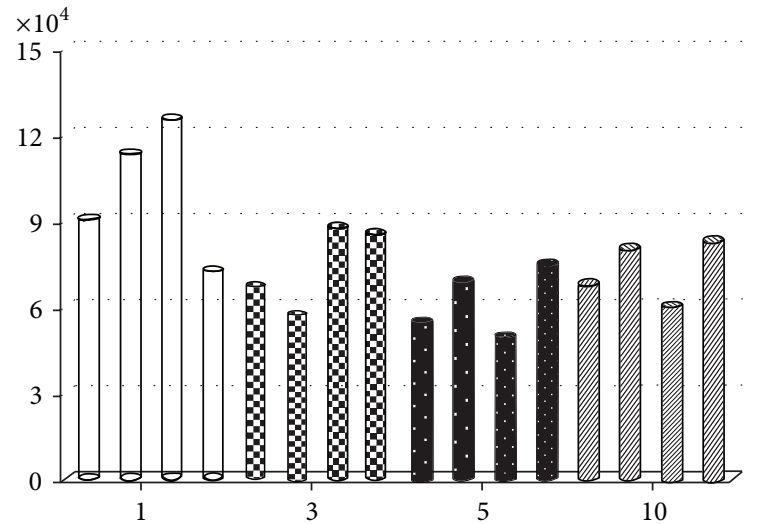

(m)

(a)

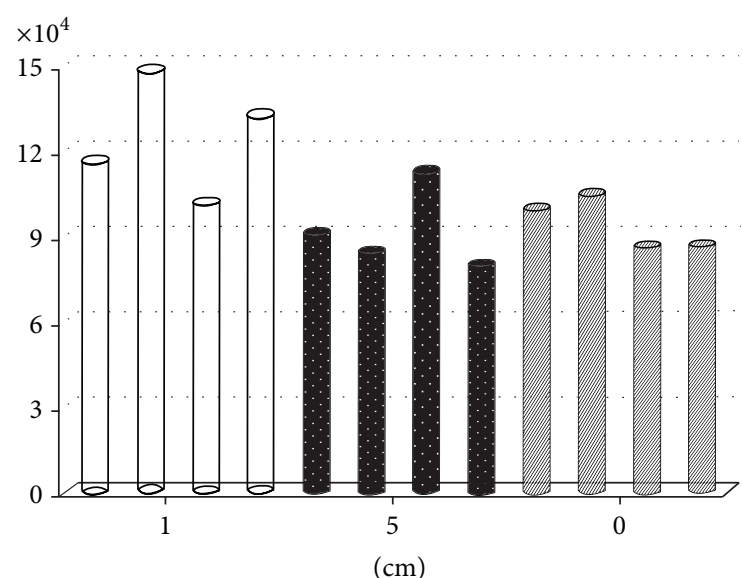

(b)

FIGURE 5: Total counts of the radiation sensor (a) according to the length of the transmitting optic fiber and (b) according to the distance between the radiation sensor and source.

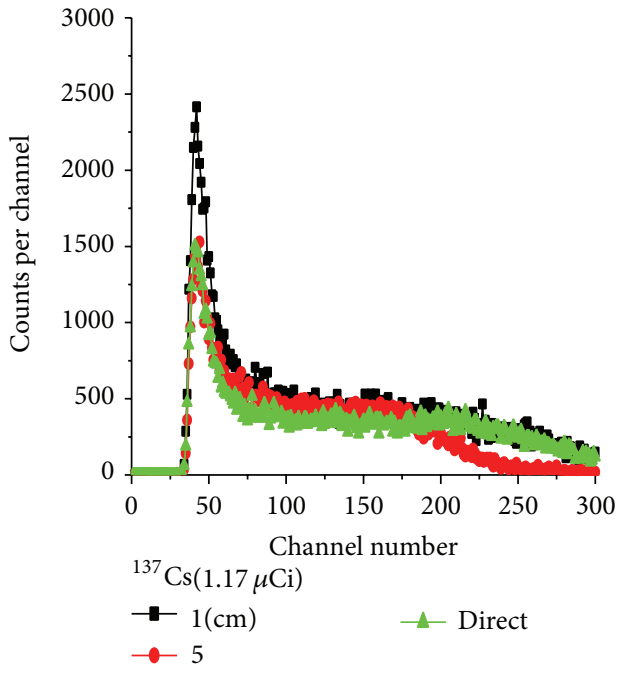

(a)

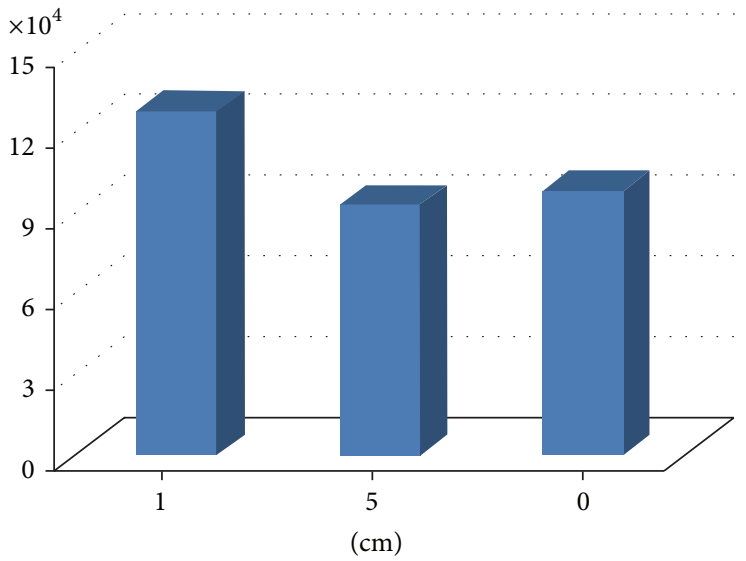

(b)

FIGURE 6: Pulse height spectra on the distance between the radiation sensor and source.

Figure 6 shows the pulse height spectra and means total counts as a function of the distance between the sensor and source. The comparison of the distance of $1 \mathrm{~cm}$ and the others showed that the pulse height at a distance of $1 \mathrm{~cm}$ was approximately $16-20 \%$ higher than the others. In this case, if the radiation sensor is located collinearly with the source, the signal detection efficiency decreased because the reaction area of the scintillator was relatively small.

The LYSO crystals have intrinsic radioactivity due to the Lu-176 isotope. ${ }^{176} \mathrm{Lu}$ is a beta-emitter primarily decaying to an excited state of ${ }^{176} \mathrm{Hf}$. This isotope emits gamma photons with energies of $307 \mathrm{keV}, 202 \mathrm{keV}$, and $88 \mathrm{keV}$ [12]. The crystal's self-emission causes the crystal to be excited and produce scintillation light. This results in a self-count of $39 \mathrm{cps} / \mathrm{g}$ [13]. From this, it was evaluated that the intrinsic radioactivity included in the LYSO scintillator used in this study contributed to $8 \sim 10 \%$ of the total counts.
Reviewing all the measurements shows that the differences in the detection efficiencies of the fiber-optic sensors were due primarily to the geometrical arrangements of fiberoptic sensors and radiation source and polishing of the fiberoptic sensors and the connecting conditions between the scintillator and transmitting fiber. The polishing of LYSO scintillator and transmitting and the connection between them were manually performed. Hence, the connecting conditions could be a little different at each experiment.

\section{Conclusion}

Using an inorganic scintillator and plastic optic fiber, the fiber-optic radiation sensor was developed and tested to examine the feasibility for remote detection of gamma rays in areas that are difficult to access, such as the spent fuel pool. The sensors were tested against a Cs-137 source, and 
the test measurements were assessed according to the length of the transmitting optic fiber and the distance between the sensor and source. The measurements show that it is possible to measure the radioactive level remotely in a spent fuel pool, and so forth, using the optic fibers and an inorganic scintillator. This auxiliary radiation sensor is expected to have merit in cross-checking the main radiation level monitoring system simultaneously and minimizing the possibility of misjudging the situation in a spent fuel pool. The fiber-optic sensor was expected to enhance the stability and efficiency to minimize the radiation exposure of workers.

\section{Conflict of Interests}

The authors declare that there is no conflict of interests regarding the publication of this paper.

\section{Acknowledgment}

This study was supported by a National Research Foundation of Korea (NRF) grant funded by the Korean Government (MSIP) (Research Project no. NRF-2012M2A8A1027833).

\section{References}

[1] A. F. Fernandez, B. Brichard, S. O'Keeffe et al., "Real-time fibre optic radiation dosimeters for nuclear environment monitoring around thermonuclear reactors," Fusion Engineering and Design, vol. 83, no. 1, pp. 50-59, 2008.

[2] H. Bueker, F. W. Haesing, S. Nicolai, and B. Wolters, "Fiber-optic radiation dosimetry for medical applications," in Optical Fibers in Medicine V, A. Katzir, Ed., vol. 1201 of Proceedings of SPIE, pp. 419-429, January 1990.

[3] M. C. Decreton, V. Massaut, and P. Borgermans, "Potential benefit of fibre optics in nuclear applications: the case of the decommissioning and the waste storage activities," in Optical Fibre Sensing and Systems in Nuclear Environments, vol. 2425 of Proceedings of SPIE, pp. 2-10, September 1994.

[4] B. Brichard, A. F. Fernandez, H. Ooms, P. Borgermans, and F. Berghmans, "True dose rate enhancement effect in phosphorous doped fibre optic radiation sensors," in 2nd European Workshop on Optical Fibre Sensors, J. M. Lopez-Higuera and B. Culshaw, Eds., vol. 5502 of Proceedings of SPIE, pp. 184-187, esp, June 2004.

[5] A. Fernandez Fernandez, P. Rodeghiero, B. Brichard et al., "Radiation-tolerant Raman Distributed Temperature monitoring system for large nuclear infrastructures," IEEE Transactions on Nuclear Science, vol. 52, no. 6, pp. 2689-2694, 2005.

[6] C. W. E. van Eijk, "Inorganic scintillators in medical imaging," Physics in Medicine and Biology, vol. 47, no. 8, pp. R85-R106, 2002.

[7] J. A. Mares, A. Beitlerova, M. Nikl et al., "Scintillation response of Ce-doped or intrinsic scintillating crystals in the range up to $1 \mathrm{MeV}$," Radiation Measurements, vol. 38, no. 4-6, pp. 353-357, 2004.

[8] V. V. Nagarkar, T. K. Gupta, S. R. Miller, Y. Klugerman, M. R. Squillante, and G. Entine, "Structured csi(tl) scintillators for $\mathrm{X}$ ray imaging applications," IEEE Transactions on Nuclear Science, vol. 45 , no. 3, pp. 492-496, 1998.
[9] S. Blahuta, A. Bessiere, D. Gourier, V. Ouspenski, and B. Viana, "Effect of the X-ray dose on the luminescence properties of Ce:Lyso and co-doped Ca, Ce:Lyso single srystals for scintillation applications," Optical Materials, vol. 35, pp. 1865-1868, 2013.

[10] I. Valais, C. Michail, S. David, C. D. Nomicos, G. S. Panayiotakis, and I. Kandarakis, "A comparative study of the luminescence properties of LYSO:Ce, LSO:Ce, GSO:Ce and BGO single crystal scintillators for use in medical X-ray imaging," Physica Medica, vol. 24, no. 2, pp. 122-125, 2008.

[11] http://www.apace-science.com/.

[12] P. E. Valk, D. L. Bailey, D. W. Townsend, and M. N. Maisey, Positron Emission Tomography: Basic Science and Clinical Practice, Springer, 3rd edition, 2003.

[13] J. Sæterstøl, Characterization of Scintillation Crystals for Positron Emission Tomography, University of Bergen, Bergen, Norway, 2010. 


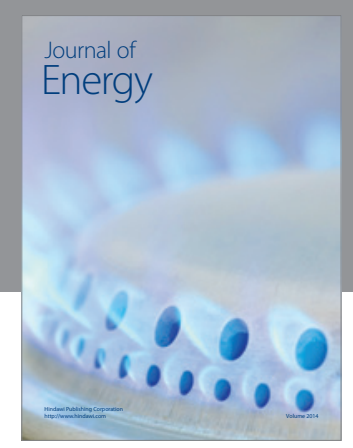

Journal of

Industrial Engineering
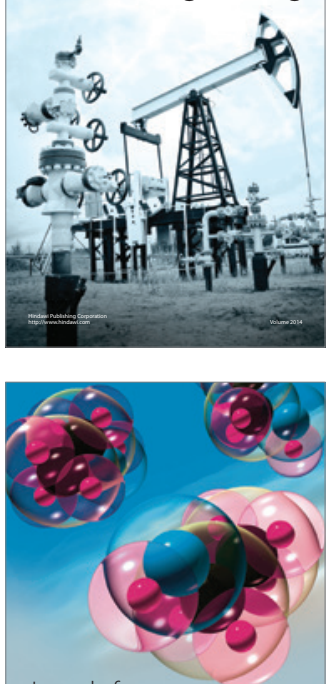

Fuels
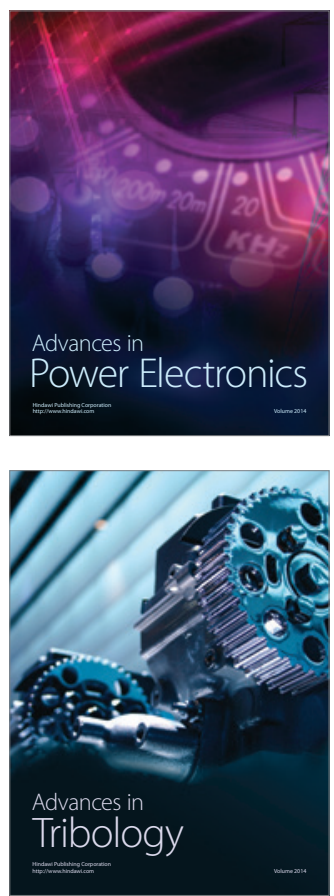

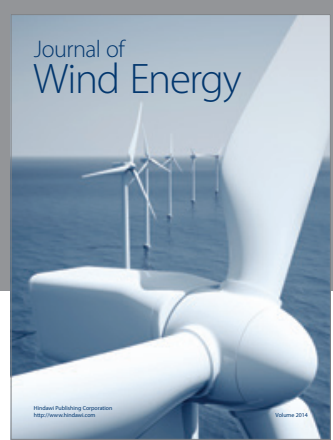

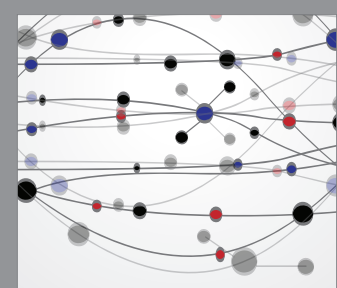

The Scientific World Journal

Submit your manuscripts at http://www.hindawi.com

Journal of

Structures
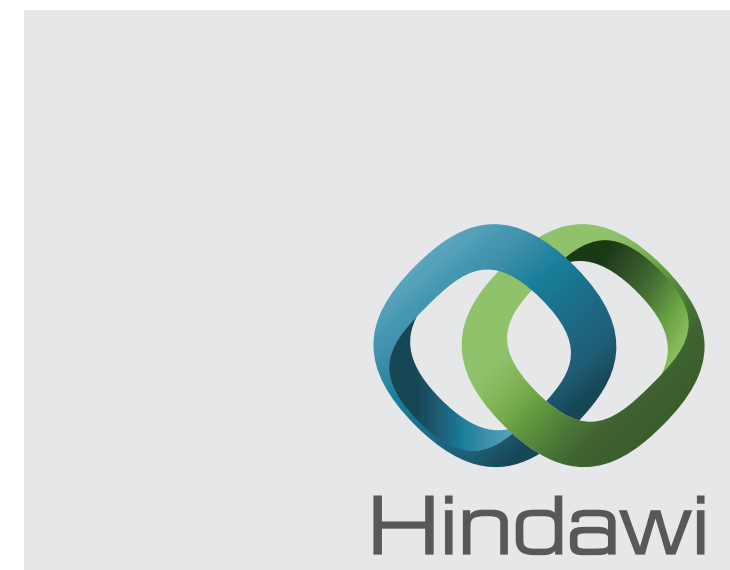

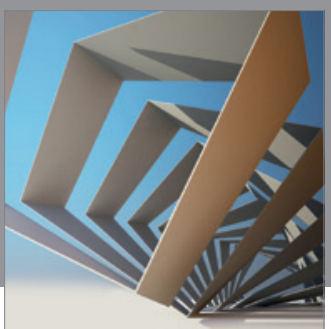

Rotating

Machinery
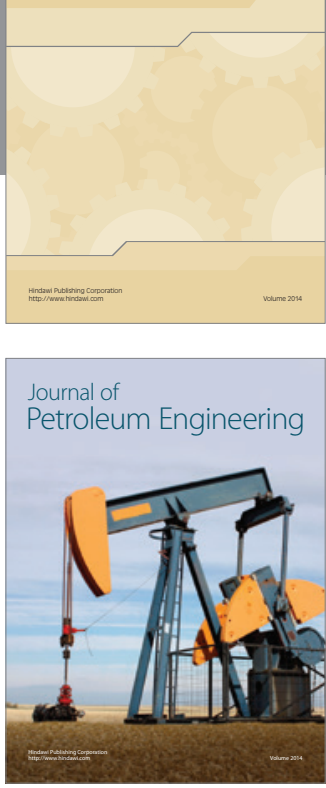

Journal of

Solar Energy
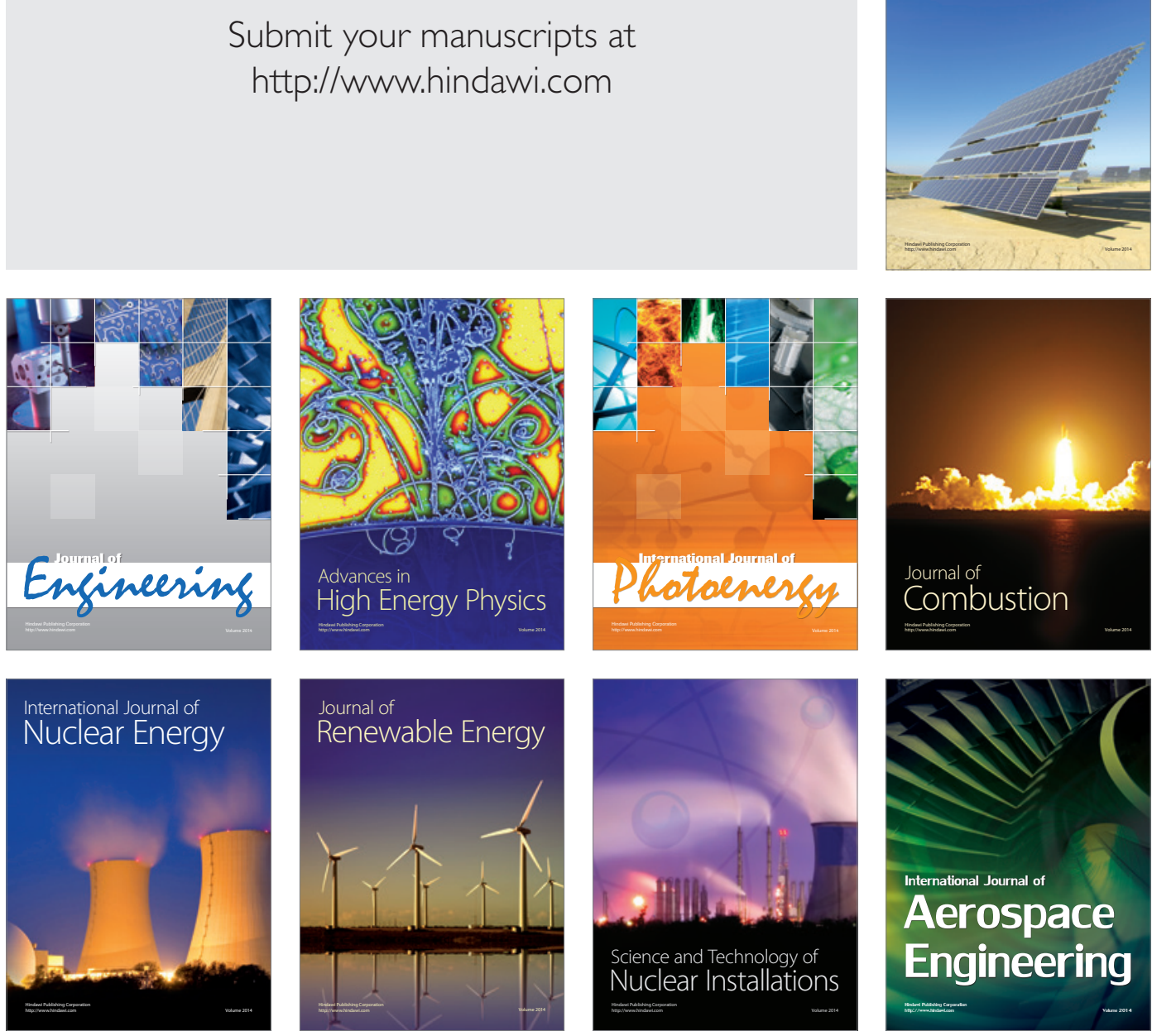